\title{
Características anatômicas de três madeiras tropicais
}

As pesquisas com anatomia da madeira englobam os estudos com as características macroscópicas e microscópicas. As macroscópicas descrevem as características vistas a olho nu, ou em equipamentos que aumentam até 10x, e também as propriedades organolépticas, que são aqueles referentes à cor, odor, gosto, brilho, desenhos da madeira e textura. As características microscópicas reúnem aspectos morfológicos relacionados as células estruturais, condutoras, reserva e armazenamento, e para serem visualizadas precisam do auxílio de microscópio. Os estudos das características anatômicas são importantes para auxiliarem na escolha da madeira em termos de qualidade e uso, além de ajudarem na classificação botânica das espécies. Sendo assim, esta pesquisa objetivou analisar as características anatômicas de três espécies florestais nativas, cujas madeiras são comercializadas dentro e fora do estado de Mato Grosso. Especificamente foram avaliadas, de forma subjetiva, as cores das madeiras e de forma simplificada, as propriedades anatômicas microscópicas. Na descrição subjetiva da cor foi utilizado a carta de Munsell, e para os estudos microscópicos foram feitas macerações pelo método de Jeffrey. Todas as análises anatômicas tiveram como referência as metodologias descritas nas normas COPANT (1973), IAWA (1989) e as modificações sugeridas por Barrichelo et al. (1976), Ramalho (1987), Burger et al. (1991), Coradin et al. (1992). Ao final da pesquisa concluiu-se que a cor predominante nas madeiras foi a marrom, porém, a cor amarela também estava presente. Anatomicamente as estruturas visualizadas com maior frequência foram os elementos de vaso do tipo solitários, com poros distribuídos em porosidade difusa perfurações simples e pontuações alternas. Na caracterização do parênquima axial houve predominância do paratraqueal e no parênquima radial houve maio incidência de parênquimas heterogêneos, com células no formato procumbentes. Em relação ao comprimento e a espessura da parede, as fibras foram classificadas, respectivamente, como sendo curtas e finas. Na análise de qualidade das fibras, as três espécies mostraram-se morfologicamente propensas para a construção civil. Contudo, a madeira de Erisma uncinatum (Cedrinho) apresentou índices de qualidade promissores para o setor de polpa celulósica e papel.

Palavras-chave: Colorimetria; Espécies nativas; Qualidade da madeira.

\section{Anatomical characteristics of three tropical woods}

Research on wood anatomy encompasses studies with macroscopic and microscopic characteristics. Macroscopes describe the characteristics seen with the naked eye, or in equipment that increase up to $10 x$, and also the organoleptic properties, which are those related to color, odor, taste, brightness, wood designs and texture. The microscopic characteristics bring together morphological aspects related to structural, conductive, reserve and storage cells, and to be visualized they need the aid of a microscope. The study of anatomical characteristics is important to assist in the choice of wood in terms of quality and use, in addition to helping in the botanical classification of species. Therefore, this research aimed to analyze the anatomical characteristics of three native forest species, whose wood is sold inside and outside the state of Mato Grosso. Specifically, the colors of the woods were evaluated subjectively and in a simplified way, the microscopic anatomica properties. In the subjective description of the color, the Munsell chart was used, and for microscopic studies, macerations were made using the Jeffrey method. All anatomical analyzes were based on the methodologies described in the COPANT (1973), IAWA (1989) standards and the modifications suggested by Barrichelo et al. (1976), Ramalho (1987), Burger et al. (1991), Coradin et al. (1992). At the end of the research it was concluded that the predominant color in the woods was brown, however, the yellow color was also present. Anatomically, the structures most frequently seen were the solitary vessel elements, with pores distributed in diffuse porosity, simple perforations and alternating scores. In the characterization of the axial parenchyma there was a predominance of the paratracheal and in the radial parenchyma there was a higher incidence of heterogeneous parenchyma, with cells in the shape of procumbents. Regarding the length and thickness of the wall, the fibers were classified, respectively, as being short and thin. In the analysis of fiber quality, the three species proved to be morphologically prone to civil construction. However, the wood of Erisma uncinatum (Cedrinho) showed promising quality indexes for the cellulose pulp and paper sector.

Keywords: Colorimetry; Native species; Wood quality.

Topic: Ciências Florestais

Reviewed anonymously in the process of blind peer.
Received: $11 / 07 / 2020$

Approved: $23 / 10 / 2020$
Gabriella da Silva França (iD)

Universidade Federal de Mato Grosso, Brasil http://lattes.cnpq.br/4835623221890401

http://orcid.org/0000-0002-8962-0796

gabriellafranca10@hotmail.com

Zaíra Morais dos Santos Hurtado de Mendoza (it) Universidade Federal de Mato Grosso, Brasil http://lattes.cnpq.br/7829408545924908

http://orcid.org/0000-0002-0930-7928 zairamorais09@gmail.com

Pedro Hurtado de Mendoza Borges (iD Universidade Federal de Mato Grosso, Brasil http://lattes.cnpq.br/0310556104378957 http://orcid.org/0000-0001-7603-8775 pborges@ufmt.br
Lila Mabel Gamarra Ruiz Diaz (iD) Universidad Nacional de Asunción, Brasil http://lattes.cnpq.br/6531730225026741 http://orcid.org/0000-0001-8230-2122 lila.gamarra@gmail.com

Esther Saraiva Carvalho de Souza (iD) Universidade Federal de Mato Grosso, Brasi http://lattes.cnpq.br/2503555162918718 http://orcid.org/0000-0002-3773-3270 esthersaraiva31@gmail.com

\section{Rayza Mariane da Silva França (iD)}

Universidade Federal de Mato Grosso, Brasil http://lattes.cnpq.br/1594563650270991 http://orcid.org/0000-0001-9120-0558 rayzafranca@hotmail.com
Pedro Hurtado de Mendoza Morais (iD Universidade Federal de Mato Grosso, Brasil http://lattes.cnpq.br/9517941254638374 http://orcid.org/0000-0003-2431-9262 pedromorais08@hotmail.com 


\section{INTRODUÇÃO}

As pesquisas com anatomia da madeira englobam os estudos com as características macroscópicas e microscópicas. As macroscópicas descrevem as características vistas a olho nu ou em equipamentos que aumentam até 10x, e também as propriedades que podem ser percebidas pelos sentidos humanos, como cor, odor, gosto, brilho, desenhos da madeira e textura. As características microscópicas reúnem aspectos relacionados as células estruturais, condutoras, reserva e armazenamento, e que para serem visualizadas precisam do auxílio de microscópios.

A cor das madeiras pertence ao grupo das propriedades organolépticas percebidas pela nossa visão e sendo nesse caso subjetiva, pois depende da percepção visual do observador. Os compostos químicos chamados de extrativos são os responsáveis pelas cores das madeiras e se concentram no cerne, inclusive, a cor das madeiras deve ser verificada no cerne e não no alburno.

Em madeiras nativas, a cor é uma característica importante pois serve para agrupar as espécies e também para valorizá-las esteticamente na indústria de processamento mecânico. A coloração da madeira pode variar significativamente de uma espécie florestal para outra, podendo existir madeiras com coloração amarela, avermelhada, alaranjada, bem como em tons de roxo (MORI et al., 2005).

Com o intuito de padronizar a descrição das cores existem os métodos subjetivos (comparativos) e os objetivos (quantitativo). O método comparativo ou sistema de ordenação de cores mais conhecido é o sistema Munsell que tem como base um atlas de cor, que serve para selecionar, medir e comparar a aparência dos objetos. Por sua vez, o método quantitativo mais utilizado é a colorimetria, a ciência da medição da cor (GONÇALEZ et al., 2001).

Além da cor, as outras propriedades organolépticas e também as características macroscópicas e microscópicas são importantes para se predizer os usos das madeiras. De forma geral, segundo Burger et al. (1991), o estudo anatômico da madeira compreende a identificação dos diversos tipos de células que constituem o lenho, suas funções, organização e peculiaridades estruturais, com o objetivo de conhecer a madeira visando direcioná-la ao seu melhor uso final. Dentre todas as características presentes na madeira, as características anatômicas macroscópicas são aquelas que podem ser observadas sem o auxílio de lentes ou seja, a olho nu. As propriedades encontradas estão ligadas à forma, tamanho ou distribuição dos elementos celulares, como vasos, parênquima axial e raios parenquimáticos.

Na análise macroscópica de madeiras é possível observar as características mais simples, como coloração, odor, textura e cheiro, por serem características fáceis de serem identificadas, requerendo pouco ou nenhum equipamento para sua identificação. Quando comparado à identificação microscópica, esse método possui muitas vantagens, pois é fácil de ser executado, rápido e não oneroso. Botosso (2011), menciona que esse procedimento permite a identificação da maioria das madeiras comerciais conhecidas atualmente no país, mas pode ser considerado bastante restritivo quando é necessária uma avaliação com maior riqueza de detalhes relacionados à estrutura anatômica, como no caso de espécies florestais pouco conhecida e muito similares, o que dificulta na prática o reconhecimento dessas madeiras. 
O entendimento sobre a estrutura anatômica da madeira é uma importante ferramenta para a sua identificação, sendo também um subsídio essencial para diferenciar espécies. Contudo, identificar corretamente uma espécie depende também de treinamento e conhecimentos profundos sobre anatomia do lenho (ZENID et al., 2007). A dissociação dos tecidos é o único método capaz de revelar as particularidades das células e consiste na redução do tecido vegetal em partículas menores. Dentre elas, a maceração é a mais comumente utilizada, sendo uma forma artificial de separação das células de um tecido, através da dissolução da lamela média, que é composta basicamente por lignina. Utilizando-se dessa técnica é possível observar tridimensional células da madeira, facilitando o estudo das características anatômicas (EVANGELISTA et al., 2009).

Freitas et al. (2015) descrevem que o estudo anatômico da madeira tem como principal objetivo verificar a relação entre as características estruturais e seu uso. As fibras, por exemplo, são elementos importantes para a escolha de uma espécie para a produção de polpa e papel e os principais parâmetros avaliados são o seu comprimento, largura, espessura e a inter-relação entre essas dimensões.

A tecnologia florestal trabalha cada vez mais a favor do uso completo e racional das árvores, assim, a correta identificação de espécies e o conhecimento de suas propriedades são elementos essenciais para atender o mercado consumidor (PAULA, 2003). O conhecimento das propriedades da madeira fornece suporte para adaptar as espécies florestais para diversos fins, como construção civil, móveis, serrarias, celulose e papel e celulose, permitindo seu melhor uso tecnológico (VALENTE et al., 2013).

É de extrema relevância o estudo sobre as características anatômicas da madeira, visto que, através delas, novos usos poderão ser analisados, reavaliados e aplicados. Diante do exposto, o objetivo dessa pesquisa foi estudar as características anatômicas de três espécies florestais nativas, amplamente comercializadas dentro e fora do estado de Mato Grosso. Especificamente foram analisadas, de forma subjetiva, as cores das madeiras e de forma simplificada, os principais elementos anatômicos a nível microscópico.

\section{MATERIAIS E MÉTODOS}

A coleta do material foi realizada no depósito unificado de madeira apreendida pertencente ao INDEA/MT, em Cuiabá, MT. No local as espécies estavam distribuídas em lotes, organizados em forma de pilhas de madeira serrada, e numeradas sequencialmente para posterior identificação. Cada indivíduo apreendido possuía um termo circunstanciado de ocorrência (TCO) único, referente a apreensões de lote de madeiras, em momentos distintos por parte da autoridade policial. Depois de apreendidas as madeiras são identificadas botanicamente por peritos do próprio órgão, através da estrutura macroscópica das mesmas.

Após a escolha aleatória dos lotes, referentes aos anos de 2016, 2017, 2018 foram separadas três espécies nativas, amplamente comercializadas dentro e fora do estado, na forma de peças serradas e derivados madeireiros (Quadro 1). Sequencialmente procedeu-se à coleta das amostras nos lotes escolhidos, amostrando-se três tábuas por espécie, resultando assim em nove tábuas. A retirada das tábuas foi feita no interior da pilha, evitando-se possíveis problemas causados por biodegradação ou intemperismo. 
Quadro 1: Espécies, gêneros e famílias estudadas.

\begin{tabular}{|l|c|c|c|}
\hline Nome Vulgar & Gênero/Espécie & Ordem & Família \\
\hline Cedrinho & Erisma uncinatum & Myrtales & Vochysiceae \\
\hline Cupiúba & Goupia glabra & Malpighiales & Goupiaceae \\
\hline Itaúba & Mezilaurus itauba & Laurales & Lauraceae \\
\hline
\end{tabular}

Fonte: INDEA/MT (2019).

Todas as tábuas foram coletadas com as medidas nominais produzidas para a sua comercialização, cujas dimensões variaram de 2,20 m a 3,00 m de comprimento, por 0,25 a 0,40 m de largura, por 3,0 cm a $7,0 \mathrm{~cm}$ de espessura. Posteriormente, o material foi separado por espécies e em seguida, cada tábua foi seccionada em cinco peças de 30,0 cm de comprimento, que foram redimensionadas para as dimensões de $8,0 \mathrm{~cm} \times 2,0 \mathrm{~cm} \times 25,0 \mathrm{~cm}$ (largura, espessura e comprimento respectivamente), totalizando ao final, quarenta e cinco amostras (15 por espécie) que foram utilizadas na seleção dos corpos de prova. Após seleção foram escolhidos trinta corpos de prova (10 por espécie), cujas medidas finais foram de $8,0 \mathrm{~cm}$ de comprimento $\mathrm{x}$ $4,0 \mathrm{~cm}$ de largura $\times 2,0 \mathrm{~cm}$ de espessura. Os outros quinze corpos de prova (5 de cada espécie) foram descartados por não atenderem as exigências das normas de ensaio.

A análise de cor das madeiras foi feita pelo método subjetivo de comparação visual de cores, com o auxílio da Carta de Munsell para Solos (MUNSELL SOIL COLOR COMPANY, 1950) que é também recomendada para uso em análises de tecidos vegetais (BURGER et al., 1991). O ensaio foi realizado colocando-se à carta diretamente em cima da amostra úmida do cerne das madeiras, observando-se através de comparação visual e a escala numérica, qual a cor que mais se aproximava da cor real do cerne da madeira. Esse ensaio foi feito utilizando-se os dez corpos de prova de cada espécie como sendo a repetição.

Visando a caracterização microscópica das células individualizadas executou-se os ensaios de maceração, utilizando-se o método Jeffrey. Para esse ensaio foram confeccionados palitos de madeira, os quais foram tratados com uma solução de ácido acético glacial $(99,8 \%)$ e peróxido de hidrogênio (20 volumes) na proporção de 1:1. Ao todo foram analisadas nove amostras de macerado, sendo três repetições por espécie, cada repetição continha três palitos (CORADIN et al., 1992).

Para obtenção do macerado (deslignificação das células), os palitos de madeira embebidos na solução foram levados à estufa, com temperatura ajustada para $70^{\circ} \mathrm{C}$, por 6 horas. Após a deslignificação lavou-se cada macerado com água destilada, até que não houvesse mais a presença de resíduos da solução. As amostras foram manualmente homogeneizadas e em seguida foram coradas utilizando-se o corante biológico safranina. O objetivo do uso do corante foi para melhorar a visualização e distinção dos tecidos vegetais e consequentemente, facilitar o estudo das estruturas anatômicas (RAMALHO, 1987).

Após coloração, o material foi visualizado em microscópio de luz modelo Olympus CX21, acoplado à câmera fotográfica, para capturar as imagens dos elementos de vasos, parênquimas e fibras. Sequencialmente efetuou-se as medições das fibras utilizando-se o programa Image-Pro Plus (MEDIA CYBERNETICS, 2002). O comprimento da fibra foi medido através da objetiva de $10 \mathrm{x}$, enquanto a largura da fibra, a largura do lúmen e a espessura da parede dupla foram medidas com o uso da objetiva de $40 \mathrm{x}$.

$\mathrm{Na}$ identificação e caracterização dos elementos anatômicos foram utilizadas cinco lâminas provisórias para cada espécie. Após a identificação e caracterização procedeu-se as medições somente das 
fibras, visto que esse elemento anatômico é muito exigido em relação aos usos das madeiras. Ao todo foram medidas cinquenta fibras por espécie, sendo feita dez medições por lâmina. Os resultados foram expressos na forma de média final, e serviram para o cálculo de alguns índices de qualidade das fibras, tais como coeficiente de flexibilidade (CF), coeficiente de rigidez (CR), fração parede (FP) e índice de Runkel (IR). Os dados de índices de qualidade foram analisados com o uso de estatística descritiva utilizando-se o programa R (R CORE TEAM, 2019).

Todas as análises anatômicas tiveram como referência as metodologias descritas nas normas COPANT (1973), IAWA (1989) e as modificações sugeridas por Barrichelo et al. (1976), Ramalho (1987), Burger et al. (1991), Coradin et al. (1992).

\section{RESULTADOS E DISCUSSÃO}

\section{Análise da cor das madeiras}

De acordo com a carta de Munsell, a cor predominante nas madeiras foi a marrom, estando presente em duas das três espécies analisadas (Quadro 2). Visualmente, a cor amarela da Goupia glabra (Cupiúba), mostrou-se diferenciada em relação às outras duas, entretanto, nas madeiras de Erisma uncinatum (Cedrinho) e de Mezilaurus itauba (Itaúba), os tons marrons eram bem semelhantes.

Quadro 2: Resultados da análise de cor de acordo com a Carta de Munsell.

\begin{tabular}{|l|c|c|c|}
\hline \multicolumn{1}{|c|}{ Nome Vulgar } & Gênero/Espécies & Código da Carta de Munsell & Cor Predominante \\
\hline Cedrinho & Erisma uncinatum & 10YR 4/4 & Marrom claro \\
\hline Cupiúba & Goupia glabra & $5 Y R 6 / 4$ & Amarelo claro \\
\hline Itaúba & Mezilaurus itauba & $2.5 Y 5 / 6$ & Marrom claro \\
\hline
\end{tabular}

A cor do cerne auxilia na classificação botânica da espécie. Além disso, as madeiras mais escuras tendem a ser mais desejadas pelo consumidor em termos de estética, e também são naturalmente mais duráveis, pois apresentam uma concentração maior de compostos fenólicos que lhes conferem durabilidade natural (CAMARGOS et al., 2001).

Zaque et al. (2019) avaliando as cores de algumas madeiras tropicais verificaram que as cores marrom-oliva, amarelo-amarronzado e marrom-claro foram as mais frequentes e que as madeiras tiveram uma tendência de ser mais amarelas que vermelhas, sendo que as mais claras apresentaram menores massas específicas, e as mais escuras resultaram em maiores massas específicas.

Panshin et al. (1970) explicam que a percepção da cor da madeira é oriunda da presença de compostos químicos minoritários denominados de extrativos. Esses compostos estão presentes na escala macroscópica no cerne das espécies arbóreas e na escala microscópicas eles se localizam nos espações intercelulares. Suas funções são diversificadas, mas além de conferirem diferentes cores aos materiais arbóreos, eles também são responsáveis odor e gosto também. Alguns destes extrativos são tóxicos para fungos, insetos e agentes marinhos xilófagos, razão pela qual frequentemente madeiras de cores escuras apresentam grande durabilidade natural (BURGER et al., 1991).

A utilização da cor como uma variável de agrupamento de espécies é uma prática comum na área de 
comercialização de madeira. Normalmente as madeiras são agrupadas em padrões já consagrados os quais são bem conhecidos pelos consumidores. Entretanto, apesar da semelhança em suas cores, a identidade anatômica (macro e microscópica) das espécies é única e bem diferenciada, o que torna essas características ferramentas úteis na fiscalização das madeiras comercializadas, colaborando assim, com a preservação das espécies.

Nisgoski et al. (2003) estudando a cor e anatomia de diferentes madeiras tropicais, agruparam as espécies de Swietenia macrophylla King. (Mogno), Entandrophragma cylindricum Sprage (Sapele), Carapa guianensis Aubl. (Andiroba), Cedrela sp. (cedro), Cariniana sp. (Jequitibá), Hymenaea sp. (Jatobá) e Nectandra rubra Mez. (Louro Vermelho) no mesmo grupo, segundo sua cor e suas características macroscópicas. Todas essas espécies tem uma cor avermelhada e são comercializadas com o padrão de Mogno.

Entretanto, elas se diferem microscopicamente pelo tipo de agrupamento e tamanho dos poros, bem como pelo tipo de parênquima e pela estratificação de seus raios. Esses autores também agruparam as espécies Balfourodendron riedelianum Engl. (Pau Marfim), Chrysophyllum sp. (Marfim Arana), Maquira guianensis Aubl. (Muiratinga), Simarouba sp. (Marupá), Parahancornia amapa (Huber) Ducke (Amapá Amargoso) e Brosimum parinarioides Ducke (Amapá Doce) em um só grupo por apresentarem coloração amarela e por serem comercializadas no padrão do Pau marfim, contudo são também diferentes pelo tipo de agrupamento, tamanhos e tipos de poros, além de serem diferentes no tipo de parênquima e estratificação dos raios.

\section{Características dos elementos anatômicos}

As madeiras analisadas apresentaram elementos de vasos predominantemente solitários, com poros distribuídos em porosidade difusa e pontuações alternas (Quadro 3).

Quadro 3: Caracterização anatômica simplificada dos elementos de vasos.

\begin{tabular}{|l|c|c|c|c|}
\hline Gênero/Espécie & Tipo de Placa de Perfuração & Tipo de Pontuação & Agrupamento de Poros & Tipo de Porosidade \\
\hline Erisma uncinatum & Múltipla Reticulada & Alterna & Solitarios & Difusa \\
\hline Goupia glabra & Escalariforme & Alterna & Solitarios & Difusa \\
\hline Mezilaurus itauba & Simples & Alterna & Solitarios & Difusa \\
\hline
\end{tabular}

Em relação ao parênquima axial houve maior frequência do paratraqueal em faixas e no parênquima radial predominou os raios heterogêneos com células em formato procumbente, variando as fileiras de células em arranjos uni,bi e multiseriado (Quadro 4).

Quadro 4: Caracterização anatômica simplificada dos parênquimas axial e radial.

\begin{tabular}{|l|c|c|c|c|}
\hline \multirow{2}{*}{ Gênero/Espécie } & \multicolumn{4}{|c|}{ Classificação dos Parênquimas } \\
\cline { 2 - 5 } & \multirow{2}{*}{ Axial } & \multicolumn{3}{c|}{ Radial } \\
\cline { 2 - 5 } & & Tipo & Formato de Célula & Fileiras de Células \\
\hline Erisma uncinatum & Paratraqueal em faixas & Heterogêneo & Ereta & Bisseriado \\
\hline Goupia glabra & Paratraqueal em faixas & Heterogêneo & Procumbentes & Multisseriado \\
\hline Mezilaurus itauba & Paratraqueal escasso & Heterogêneo & Procumbentes & Multisseriad \\
\hline
\end{tabular}

Prata et al. (2009), em seus estudos com a espécie amazônica Maytenus guyanensis (Chichuá), concluíram que o parênquima axial e radial são características anatômicas importante para o metabolismo 
do vegetal, e que sua abundância nas plantas nativas da região amazônica está associada ao acúmulo e mobilização de metabólitos, atuando como uma possível adaptação das plantas às condições em que as taxas fotossintéticas são altas, o que propicia o surgimento de indivíduos adultos com expressivos diâmetros em altura e diâmetro, tornando-os potenciais fornecedores de madeira.

De acordo com a Tabela 1, as fibras da madeira de Mezilaurus itauba (Itaúba) apresentaram os maiores valores de comprimento, largura, espessura de parede e diâmetro de lúmen. Em relação ao comprimento e espessura da parede, as fibras foram classificadas, respectivamente, como sendo curtas e finas, conforme IAWA (1989). De forma geral, os valores dos índices de qualidade das fibras apresentaram baixo desvio padrão, resultando em pequenos coeficientes de variação, o que demonstra uma boa condução do experimento.

Tabela 1: Valores médios das dimensões das fibras e seus respectivos índices de qualidade.

\begin{tabular}{|c|c|c|c|c|}
\hline \multirow[b]{2}{*}{ Gênero/Espécie } & \multicolumn{4}{|c|}{ Dimensões $(\mu \mathrm{m})$} \\
\hline & Comprimento & Largura & $\begin{array}{l}\text { Espessura de } \\
\text { Parede }\end{array}$ & $\begin{array}{l}\text { Diâmetro do } \\
\text { Lúmen }\end{array}$ \\
\hline Erisma ncinatum & 1427,100 & 25,260 & 10,180 & 5,908 \\
\hline Goupia glabra & 1685,700 & 29,310 & 13,120 & 5,110 \\
\hline Mezilaurus itauba & 1944,000 & 32,040 & 20,600 & 6,653 \\
\hline \multirow[b]{2}{*}{ Gênero/Espécie } & \multicolumn{4}{|c|}{ Índices de Qualidade } \\
\hline & $\begin{array}{l}\text { Coeficiente de Flexibilidade } \\
(\%)\end{array}$ & $\begin{array}{c}\text { Coeficiente de Rigidez } \\
(\%)\end{array}$ & $\begin{array}{c}\text { Fração } \\
\text { Parede (\%) }\end{array}$ & $\begin{array}{l}\text { Índice de } \\
\text { Runkell (-) }\end{array}$ \\
\hline $\begin{array}{l}\text { Erisma } \\
\text { uncinatum }\end{array}$ & $60,044^{ \pm 3,32}(5,53)$ & $0,528^{ \pm 0,02}(3,09)$ & $29,976^{ \pm 1,04}(3,48)$ & $1,033^{ \pm 0,05}(4,49)$ \\
\hline Goupia glabra & $50,159^{ \pm 2,88}(5,75)$ & $0,847^{ \pm 0,05}(5,57)$ & $32,072^{ \pm 1,03}(3,22)$ & $2,525^{ \pm 0,15}(5,98)$ \\
\hline Mezilaurus itauba & $39,608^{ \pm 1,49}(3,76)$ & $0,898^{ \pm 0,03}(3,56)$ & $45,415^{ \pm 1,96}(4,31)$ & $2,158^{ \pm 0,12}(5,54)$ \\
\hline
\end{tabular}

Expoentes precedidos por \pm representam o desvio padrão e os valores entre parênteses correspondem ao coeficiente de variação.

Segundo Panshin et al. (1970), fibras maiores conferem maior resistência mecânica às madeiras e paredes mais espessas conferem maior densidade. Ambas características são importantes para indicação de usos das madeiras. De acordo com Burger et al. (1991), a quantidade do material histológico e suas dimensões, influenciam a massa específica das madeiras e por sua vez a resistência mecânica.

Chagas et al. (2007) trabalhando com caracterização macro e microscópica da madeira de Eremanthus erythropappus, verificou que a faixa de lenho mais escura (lenho tardio) era formada por fibras de parede mais espessa, maior frequência de vasos e menor diâmetro dos vasos (isolados ou até múltiplos de 5). A faixa de lenho mais clara (lenho inicial) era formada por fibras de parede mais delgada, menor frequência de vasos e maior diâmetro dos vasos (maioria múltiplos de 3, alguns em cadeias de disposição radial ou oblíqua), ressaltando que o na faixa mais escura a resistência mecânica da madeira era bem maior do que na faixa mais clara.

Freitas et al. (2015) pesquisando a estrutura anatômica da madeira de Liquidambar sp. relataram que a madeira possui fibras libriformes, com comprimento médio de 1980,88 $\mu \mathrm{m}$ no cerne periférico, variando de curtas $(1300,72 \mu \mathrm{m})$ a longas $(2640,42 \mu \mathrm{m})$. O valor médio da largura foi de 30,83 $\mu \mathrm{m}$. O diâmetro médio do lume foi de $15,70 \mu \mathrm{m}$ e o valor médio da espessura da parede foi de $7,56 \mu \mathrm{m}$, sendo, portanto, fibras de paredes delgadas a espessas. 
Cobas et al. (2018) estudando a anatomia da madeira juvenil e adulta de Robinia pseudoacacia verificaram que o comprimento médio das fibras variara de 926 a $950 \mu \mathrm{m}$ e que elas apresentaram efeito importante sobre os principais usos dessa madeira tais como: fabricação de polpa e papel, carvão vegetal e produtos serrados.

Cahuana et al. (2019), analisando a madeira adulta de Amburana cearensis, das florestas tropicais do Peru, observaram que os valores médios das dimensões das fibras foram 24,07 $\mu \mathrm{m}$ para a largura, 13,86 $\mu \mathrm{m}$ para o lúmen, 5,11 $\mu \mathrm{m}$ para a espessura da parede e 1293,06 $\mu \mathrm{m}$ para o comprimento. Os mesmos autores também mencionaram que o comprimento das fibras foi a característica anatômica que mais contribuiu para distinguir os tecidos da espécie na direção axial. Alguns valores médios das dimensões das fibras das madeiras encontradas nessa pesquisa estão próximos aos valores médios reportados em literatura. Contudo, ressaltase que a estrutura anatômica é altamente dependente da espécie, idade, sítio e condições edafoclimáticas.

Ao se analisar os índices de qualidade das fibras, verifica-se que a madeira de Erisma uncinatum (Cedrinho) apresentou o maior valor de coeficientes de flexibilidade e os menores valores de coeficiente de rigidez, fração parede e índice de Runkel. Estes parâmetros são importantes para verificar a aptidão das madeiras para o setor de polpa celulósica e papel, bem como para o setor de construção civil, onde a qualidade da fibra serve para atestar a resistência da madeira a esforços solicitantes. Geralmente madeiras com menores índices de Runkel e maior coeficiente de flexibilidade são indicadas para produção de papel, e nessa condição, as fibras apresentam paredes mais delgadas. De acordo com Runkel (1952) tendo-se como base o índice de Runkel, avalia-se a aptidão das madeiras para o setor papeleiro, adotando-se os seguintes critérios: Grupo I - Valores do índice até 0,25: a fibra é considerada excelente para papel; Grupo II - Valores do índice variando de 0,25-0, 50: muito boa para papel; Grupo III - de 0,50 - 1,0: boa para papel; Grupo IV Valores do índice variando de 1,0 - 2,0: regular para papel; Grupo V - Valores do índice acima de 2,0: não deve ser usada para papel, tendo em vista que o grau de colapso é muito baixo. No estudo em questão, somente a madeira de Erisma uncinatum (Cedrinho), apresentou esse índice próximo de 1,0 o que a classifica como boa para papel, as outras duas madeiras apresentaram índices acima de 2,0 o que as classifica inadequadas para a produção de papel.

Gonçalez et al. (2014) descrevem que as fibras com paredes mais espessas podem ter maior teor relativo de celulose, havendo, provavelmente, uma correlação positiva entre a espessura da parede da fibra e o rendimento em produção de celulose, contudo isso irá dificultar a formação do papel, afetando as suas propriedades de resistência. Nesse caso, paredes muito espessas não seriam indicadas para produção de papel, mas poderiam ser indicadas por exemplo, para a área de construções de madeira.

Akgül et al. (2020) investigando as características morfológicas de Elaeagnus angustifólia verificaram que para essa espécie, os índices de qualidade das fibras foram abaixo do indicado para a produção de papel. Os autores também esclareceram que esses índices são costumeiramente utilizados na indústria de polpa celulósica, pois servem para predizer as qualidades de resistência do papel e seus derivados. Entretanto, eles também podem ser usados para predizer a resistência das madeiras quando submetidas a esforços mecânicos, os quais são exigidos na área de construção civil. Conforme Paula (2003) do ponto de vista 
tecnológico, as fibras sãos os elementos celulares mais importantes da madeira, por esta razão o conhecimento da quantidade desses elementos e de sua estrutura é de fundamental importância no que tange a qualificação de madeiras para usos diversos.

\section{CONCLUSÕES}

Nas madeiras estudadas, a cor predominante foi a marrom e a metodologia adotada mostrou-se eficiente na verificação das cores podendo ser utilizada para padronização de matizes madeireiras. Anatomicamente as estruturas visualizadas com maior frequência foram os elementos de vaso do tipo solitários, com porosidade difusa, perfurações simples e pontuações alternas. Na caracterização do parênquima axial houve predominância do paratraqueal em faixas, e no parênquima radial houve maior incidência do heterogêneo, com células procumbentes. Na análise das fibras, as três espécies mostraram-se propensas para a construção civil, com fibras espessas, porém, a madeira de Mezilaurus itauba (Itaúba) foi superior em relação às demais. Já em relação aos índices de qualidade da fibra, a espécie Erisma uncinatum (Cedrinho) apresentou índices promissores para o setor de polpa celulósica e papel.

As características estudadas contribuirão para a valorização e otimização dos usos dessas madeiras, uma vez que são amplamente comercializadas no mercado interno e externo. Além disso, elas servirão como ferramenta útil para identificação das madeiras serradas que passam pelos postos de fiscalização, auxiliando assim, na preservação de nossas florestas.

\section{REFERÊNCIAS}

AKGÜL, M.; AKÇA, M.. The chemical and morphological properties of oleaster. Maderas. Ciencia y tecnología, v.22, n.1, p.13-22, 2020. DOI: http://doi.org/10.4067/S0718221X202000500010213

BARRICHELO, L. E. G.; BRITO, J. O.. A madeira das espécies de eucalipto como matéria-prima para a indústria de celulose e papel. Série Divulgação PRODEPEF, Brasília, n.13, p.1-145, 1976.

BOTOSSO, P. C.. Identificação macroscópica de madeiras: guia prático e noções básicas para o seu reconhecimento. Colombo: Embrapa Florestas, 2011.

BURGER, L. L.; RICHITER, H. G.. Anatomia da madeira. São Paulo: Nobel, 1991.

CAMARGOS, J. A.; GONÇALEZ, J. C.. A colorimetria aplicada como instrumento na elaboração de uma tabela de cores de madeira. Brasil Florestal, Brasília, n.71, p.30-41, 2001.

CAHUANA, L. A. P.; LATORRACA, J. V. F.; PACE, J. H. C.; SANTOS, G. C. V.; LIMA, D. O.; RAMOS, L. M. A.; CARMO, J. F.. Variabilidad radial física y anatómica del leño de árboles de Amburana cearensis (Allemao) A.C.Sm. Colombia Forestal, v.22, n.1, p.17-26, 2019. DOI: https://doi.org/10.14483/2256201X.13083

CHAGAS, M. P.; FILHO, M. T.; LISI, C. S.. Caracterização macro e microscópica da madeira de candeia (Eremanthus erythropappus, Asteraceae). Revista Brasileira de
Biociências, Porto Alegre, v.5, n.1, p.156-158, 2007.

COBAS, A. C.; MONTEOLIVA, S.. Modelos descriptivos de distribución de madera juvenil y madura en Robinia pseudoacacia. Maderas, Ciência e Tecnologia, v.20, n.2, p.287-296, 2018. DOI: http://doi.org/10.4067/S0718$\underline{221 \times 2018005021201}$

COPANT. Comisión Panamericana de Normas Tecnicas. Descripción de características generales, macroscópicas de las maderas angiospermas dicotiledóneas. COPANT, 1974.

CORADIN, V. T. R.; MUNIZ, G. L. B.. Normas de procedimentos em estudos de anatomia da madeira. Brasília: ABNT, 1992.

EVANGELISTA, W. V.; STANCIOLA, J.. Técnicas em Anatomia da Madeira. Belo Horizongte: Universidade Federal de Viçosa, 2009.

FREITAS, T. P.; FEUCHARD, L. D.; OLIVEIRA, J. T. S.; PAES, J. B.; ARANTES, M. D. C.. Caracterizações anatômica e físicomecânica da madeira de Liquidambar sp. Floresta, v.45, n.4, p.723-734. 2015. DOI: http://doi.org/10.5380/rf.v45i4.36878

GONÇALEZ, J. C.; JANIN, G.; SANTORO, A. C. S.; COSTA, A. F.; VALLE, A. T.. Colorimetria quantitativa: uma técnica objetiva de determinar a cor da madeira. Brasil Florestal, v.20, n.72, p.47-58, 2001.

GONÇALEZ, J. C.; SANTOS, G. G.; JUNIOR, F G. S.; MARTINS, I. 
S.; COSTA, J. A.. Relações entre dimensões de fibras e de densidade da madeira ao longo do tronco de Eucalyptus urograndis. Scientia Forestalis, v.42, n.101, p.81-89, 2014.

IAWA. International Association of Wood Anatomy. List of microscopic features for hardwood identification, with an appendix on non-anatomical information. IAWA Bulletin, Leiden, v.10, n.3, p.219-332, 1989.

MEDIA CYBERNETICS. Image-Pro Plus: application notes. Silver Spring: Media Cybernetics, 2002

MORI, C. L. S. O.; LIMA, J. T.; MORI, F. A.; TRUGILHO, P. F.; GONCALEZ, J. C.. Caracterização da cor da madeira de clones de híbridos de Eucalyptus spp. Cerne, Lavras, v.11, n.2, p.137-146, 2005. DOI:

http://org.redalyc.org/articulo.oa?id=74411204

MUNSELL SOIL COLOR COMPANY. Munsell soil color chats Baltimore: Munsell color, Macbeth Division of Kollmorgen Corporation, 1950.

NISGOSKI, S.; MUÑIZ, G. I. B; CECCANTINI, G.. Caracterização anatômica macroscópica das madeiras utilizadas para laminação na região de Curitiba-PR. Scientia Agraria, v.4, n.1, 2003. DOI: http://doi.org/10.5380/rsa.v4i1.1065

PANSHIN, A. J.; ZEEUW, C.. Textbook of wood technology. 3 ed. New York: McGraw-Hill, 1970.

PAULA, J. E.. Caracterização anatômica da madeira de sete espécies da Amazônia com vistas à produção de energia e papel. Acta Amazônica, v.33, n.2, p.243-262, 2003. DOI: https://doi.org/10.1590/1809-4392200332262

PRATA, R. R.; MENDONÇA, M. S.. Estudo anatômico do xilema secundário da raiz e do caule de Maytenus guyanensis Klotzsch ex Reissek (Celastraceae). Acta Amazônica, v.39, n.2, p.261-266, 2009. DOI: http://doi.org/10.1590/S0044-59672009000200003

RAMALHO, R. S.. O uso de macerado no estudo anatômico de madeiras. Viçosa: Universidade Federal de Viçosa, 1987.

R CORE TEAM. R: A language and environment for statistical computing. Vienna: R Foundation for Statistical Computing. 2019.

RUNKEL, R. O. H.. Pulp from tropical wood. TAPPI, v.35, n.4, p.174-178, 1952.

VALENTE, B. M.; EVANGELISTA, W. V.; SILVA, J. C.; LUCIA, R. M. D.. Variabilidade radial e longitudinal das propriedades físicas e anatômicas da madeira de angico-vermelho. Scientia Forestalis, v.41, n.100, p.485-496, 2013

ZAQUE, L. A. M.; MELO, R. R.; SOUZA, E. C.; JUNIOR, L. S. Caracterização colorimétrica e da massa específica das madeiras comercializadas no Mato Grosso. Ciência da Madeira, Pelotas, v.10, n.3, p.236-246, 2019. Dol: http://doi.org/10.12953/2177-6830/rcm.v10n3p236-246

ZENID, G. J.; CECCANTINI, G. C. T.. Identificação botânica de madeiras. São Paulo: Laboratório de Anatomia e Identificação de Madeiras do Instituto de Pesquisa Tecnológica do Estado de São Paulo, 2007.

A CBPC - Companhia Brasileira de Produção Científica (CNPJ: 11.221.422/0001-03) detém os direitos materiais desta publicação. Os direitos referem-se à publicação do trabalho em qualquer parte do mundo, incluindo os direitos às renovações, expansões e disseminações da contribuição, bem como outros direitos subsidiários. Todos os trabalhos publicados eletronicamente poderão posteriormente ser publicados em coletâneas impressas sob coordenação da Sustenere Publishing, da Companhia Brasileira de Produção Científica e seus parceiros autorizados. Os (as) autores (as) preservam os direitos autorais, mas não têm permissão para a publicação da contribuição em outro meio, impresso ou digital, em português ou em tradução. 